Portland State University

PDXScholar

From Mentor to Faculty: Reflections on the Praxis of Care

Roberta Hunte

Portland State University, hunte@pdx.edu

Joseph Wightman

Portland State University, josew@pdx.edu

Follow this and additional works at: https://pdxscholar.library.pdx.edu/socwork_fac

Part of the Education Commons

Let us know how access to this document benefits you.

Citation Details

Hunte, R., \& Wightman, J. (2018). From Mentor to Faculty: Reflections on the Praxis of Care. The Journal of General Education 67(1), 136-151. https://doi.org/10.5325/jgeneeduc.67.1-2.0136

This Article is brought to you for free and open access. It has been accepted for inclusion in School of Social Work Faculty Publications and Presentations by an authorized administrator of PDXScholar. Please contact us if we can make this document more accessible: pdxscholar@pdx.edu. 


\title{
From Mentor to Faculty: Reflections on the Praxis of Care
}

\author{
ROBERT HUNTE AND JOSEPH WIGHTMAN
}

ABSTRACT | Hunte and Wightman come to teaching positions in Portland State's University Studies (general education) program after having served as graduate and undergraduate mentors in the Peer

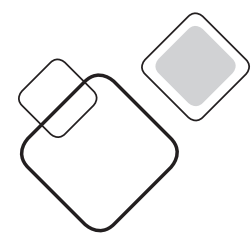
Mentor Program. The unique model employs successful graduate and upper-division undergraduate students as teaching assistants in Freshman and Sophomore Inquiry classes to promote greater student success at the university. The authors reflect on their pedagogy from the perspectives as former mentors and current faculty. They discuss how their pedagogy has evolved through roles in University Studies. This article is constructed as a dialogue, using excerpts from those conversations. It explores issues of equity and access, and the care ethic that undergirds their shared approaches to teaching.

\section{Introduction}

We began this project acquainted with each other through our involvement with University Studies, Portland State University's general education program. We were paired, as faculty members who had come through the Peer Mentor Program, to write about persistence across different levels of University Studies. We were tasked with understanding how our mentoring experiences fostered our desire to continue serving students in University Studies. We are two of many former mentors who, currently or in the past, teach or occupy staff positions in University Studies and in many departments at Portland State.

As we shared our stories over cups of coffee, we came to discover deeper meaning in our journeys and some important values that we share. We talked about the significance of the program, but our conversation seemed to always 
veer away from that central question of persistence, leading us instead to discuss how we connected our paths through higher education to the lessons we learned as students, mentors, and teachers in this community.

We write this article as a dialogue between two colleagues and friends. Our hope is to engage you, Dear Reader, as we have each other-with care and authenticity, and a sincere desire to learn from each other. We will begin with an introduction to each of us, followed by our transcribed conversation.

JW:

RH:

JW:
I identify as a working-class, White, cisgender, straight male. I am a father, partner, student, artist, and academic. I currently teach as an adjunct faculty in the University Studies Senior Capstone Program. I am a mother, partner, educator, cultural worker, and a Black feminist lower-middle-class West Indian American. I teach as a tenure track assistant professor in Senior Inquiry, which is Freshman Inquiry (FRINQ) taught to high school seniors, and Sophomore Inquiry (SINQ) sections of University Studies.

My grandparents raised me. They both were high school graduates. My grandfather and one uncle served in multiple branches of the military. The whole family was practicing Mormons. I had sporadic contact with my mother, who gave birth to me when she was 16. I moved to a youth runaway shelter at 15, dropped out of high school, and went to Job Corps when I turned 16. There, I earned a GED, learned a trade, and became a father. As with many teenage romantic relationships, mine did not last long, and I found myself raising my son alone, juggling work and parenting, and trying to figure out the world of higher education with no real guidance. I did not know to think of myself as a first-generation student, or what the implications of that identity might be.

I did not commit to furthering my education in any meaningful way until my son, at 14 , was living with his mother on the other side of the state. I had spent the better part of a decade working in construction. During those years, I was, for the first time, meaningfully exposed to difference. Most of the people that I worked with were much like me-working 
class White boys with miles of meandering paths behind them, and no clear destination ahead. But also present was a contingent of motivated, goaloriented Brown men from Latin America.

This latter group, to my surprise, were the ones that I befriended. There was something generous and genuine about this group that drew me in and had me questioning many of the assumptions that guided my choices up to that point. We labored together, shared food, celebrated each other's birthdays, sat together over a pitcher after long days in the sun. Few of them spoke English fluently, and the Spanish that I acquired was stilted, and only relevant to the job site. Despite the warmth I felt in their presence and our mutual concern for each other, I faced a wall when I attempted to close the space between us. I assumed that wall was built of words that I had not yet learned.

In 2007 I applied to Portland State, certain that learning Spanish would help me to breach that barrier. I chose the university because my wife was studying here and because I had no idea how to choose a school. My ignorance followed me throughout my studies, though I acquired some knowledge of the institutional culture along the way. I did not apply for scholarships, assuming that they were only for people less advantaged than I was. I borrowed every cent offered, unable to conceive of the eventual burden that this debt would place on my family.

I did not know how to build a degree through choosing courses. I did not visit an advisor until halfway through my junior year, and only then because one of my regular professors admonished me to do so. In that meeting, I discovered that, if I focused only on my remaining requirements, I would finish my degree with a silly number of unneeded credits. Though I had earned all of the credits (and then some) required for a minor in Spanish (I was an International Studies major), I did not think to apply for it upon graduation. I mention all of this to demonstrate how strongly I identify, 
$\mathrm{RH}$ :

certainly then, but even now-as an outsider to academia, my career choice notwithstanding.

I am technically a second-generation college grad, but can relate to some of the not knowing you mentioned as a first- generation college student. My mom is a first-generation college grad from the U.S. My father did not attend university and is from Barbados. When I was 14 my family moved from Atlanta, GA, to South Africa where my father was a national and international cricket coach. I lived in South Africa for just under ten years from 1992 to 2001. I completed high school and my bachelor's degree in Politics and English in South Africa. Both my parents emphasized education and drove home the message that we were going to college. When it came to university my parents worked to get me in and to pay for it. What I learned there was up to me. There was a disconnect between what I studied and how it was understood or discussed in my home.

I began my undergrad in 1997, shortly after the end of Apartheid in South Africa. I attended the University of the Witwatersrand, which had begun accepting more students of color. "Wits," as it is commonly known, had to meaningfully engage with the vastly inequitable South African education system that prepared White students for university and underprepared Black students for basic college-level work. The negative question of whether the university was lowering its standards to accommodate the needs of students of color was often in the air. This debate questioned whether students had the ability to rise to the academic rigor expected at an elite South African university. It failed to ask the bigger questions of what do students need to be successful learners? What knowledge do they already possess when they enter the academic arena? How can we as educators play to our students' strengths? What is the role of the university in a democratic society?

The newly established Wits Writing Centre offered an alternative approach to thinking about 
the potential of nontraditional students. The Centre, under the direction of Dr. Pamela Nichols, celebrated the stories and voices of writers and students and it showcased the rich traditions of Black and Brown radical thinking generated in the struggle against Apartheid and in the new South Africa. I joined the Centre's team of tutors in the second half of my degree. Here I found a place of academic connection for me at the school. It also engaged me in work to enhance nontraditional students' confidence and abilities to excel at Wits.

All of my education has been in predominantly White institutions. As a well-educated student of color who was often in the minority in my classes I constantly negotiated an assumption of inferiority in regards to my academic capacity, and that of students like me. In university I often felt, and still do to some extent, an imposter syndrome that I would be found out as a subpar academic. Anxiety about a failure to perform meant that I took learning seriously; however, I was not impervious to the harm of negative messages about the supposed limited capacity of students of color. This challenge has followed me throughout my academic career in three different countries.

I emigrated back to the U.S. in 2001 and moved to Portland, Oregon, where I began a master's degree in Conflict Resolution. I was directed to apply for the Peer Mentor Scholarship. I applied and was hired. On reflection, being a mentor fundamentally changed my experience of higher education.

Joe, how did your experience as a mentor expand your perspective on what it means to learn and to teach? In my undergrad I learned how to write papers and move through the university system. I was well prepared for the academic work of university from my high school education. I was well versed in the banking system of education. I knew how to show up to class, take notes, and reflect my mastery of material back to my instructor. When I began mentor training I was introduced to the ideas of Paulo Freire 
JW:

(1970). Particularly the idea that learners come to the classroom with knowledge, and the work of the teacher is to help develop the voice and wisdom that students bring, but not to be the leading authority in the classroom. Students are both learners and co-creators of knowledge. This blew my mind.

As I was a first-generation college student, the issue of access was central to my experience. When I first stepped onto a community college campus, I was directed to an admissions advisor who held my hand through the application process. I would never have been able to sign up for classes without that initial guidance. But this 15-minute meeting did not come close to making up for the cultural capital of traditional students. I often reflect on the understanding that my GED was intended to stand in for a high school diploma. If true, that says something shocking about our expectations of high school. Is the relationship between a lifetime of cultural learning and the expected services of the traditional college similar to the HS-GED relationship? Are these brief conversations with overworked, nameless functionaries assumed to fill the gaps in access and level the field for the multitude of students who are coming to higher education as if to a foreign country? If so, can the larger institution really be said to be serving without bias?

Being a student in University Studies, and later a mentor, illuminated the importance of these questions for me. And, the response that I experienced fueled my desire to teach. My mentor led me to resources, as if to say, "I know there is no map of this place; let me guide you." As a mentor myself, I was helped to understand many of the waypoints in this landscape that remained invisible to me and to so many of my peers whom I was now guiding. It was as though I'd been made privy to a secret that I was allowed to share with others whom I found bumbling around like I had done.

Mentoring was definitely my entry into understanding myself as an educator, but I think, in 
retrospect, that reading Freire was really what led me to that door. My initial encounter with Freire came when I first enrolled at Portland State in 2007 and took a SINQ course, "Popular Culture." True to the goals of the program, we were tasked with critical examination of the messages that we passively received from our environment. One of the readings we were assigned was Pedagogy of the Oppressed (Freire, 1970). Like you, I found this line of inquiry to be powerful, and I recognized that a window had been opened for me that revealed a world that was familiar and foreign at the same time. But I could not predict how it would continue to shape me throughout my career as a student, define my practice as a mentor, and rest at the heart of my pedagogy as faculty in University Studies.

The opening statement from the University Studies Teaching Ethos-How we teach is what we teach-has meaning to me, because I have often reflected on my first experience of Freire's liberating message. It is a living part of my approach to building relationships with my students. I begin each term by telling students that they enter the classroom whole, and that I have a responsibility to guide them through an experience that will have different meaning to each of them. The resulting "literacy" in the academic issues we discuss and the stories gathered from community-based learning that illustrate them become a collective empowerment to effect change and shape the world that we are destined to share. Freire speaks of liberation. My hope as an educator is to free students from the limitations that they assume for themselves and to dispel the powerlessness they feel in the face of insurmountable social problems.

RH: $\quad$ I think of Portland State's motto Let Knowledge Serve the City. The school has an ethos of community-based learning engagement and a long-standing tradition of educating diverse students from across the state. Portland State is the largest university in Oregon and has the most diverse student population in the state. In mentor training the emphasis 
was on creating greater access and opportunity for students. As a mentor we were to bring academic writing resources, scholarship information, and campus-wide opportunities into the classroom. I began to see all of these different activities on campus as opportunities to engage students' learning. It became my mission to connect students to opportunities that they would not necessarily seek out for themselves. As a teacher, I carry that orientation into my classes. Being willing to share information, whether it is considered obvious or not, is a part of creating greater access and belonging for students to the institution.

As a mentor I worked alongside professors who taught "Families and Society," "Healthy People, Healthy Places," and "Popular Culture." Those courses were not necessarily in my direct field of study. I worked with faculty partners and sophomore students. I taught three 50-minute mentor sections a week with 12 students each section on material related to the main course and some elements of how to be a good student. I liked getting to sit in on classes that I would not have taken, but were interesting. The exposure to different bodies of knowledge inadvertently caused me to deepen my interdisciplinary thinking. Elements of material in mentoring classes and my graduate work began to inform each other. The University Studies framework centers inquiry and uses interdisciplinarity as the path into material. The focus on inquiry deepened my intellectual curiosity and broadened my scope of reference. As a teacher I often ask students to think about how whatever we are studying relates to their majors. Inquiry can become a way of life.

JW: $\quad$ I have decided that Freire's literacy, in the context of my teaching at least, is defined by a capacity for inquiry. It is not-cannot be-a mere understanding of the lessons of the dominant culture, but must also entail the capacity for constant reexamination of those lessons and their shifting influence on the lives of both the oppressed and those who ally themselves 
with the movements seeking to remedy inequity. Ecological principles dictate that those identified with the dominant culture are also harmed when it motivates or perpetuates the oppression of others. This seemingly simple yet infinitely complicated idea informs my understanding of my role as an educator. Students must know that questioning does not stop with the receipt of answers. I have only recently come to realize that such an understanding is deeply rooted in an ethic of care-for my students, but also for all those whom they will impact throughout their post-baccalaureate lives.

The University Studies model is primarily about equity and access. In practice, these things are also connected to "care." How do you understand this link? Did you first see this as a mentor, or only later as you began teaching?

$\mathrm{RH}$ :

I had a model of care in my experience as a tutor at the Writing Centre in South Africa. Dr. Nichols was a teacher, mentor, and friend to me. She modeled support and encouragement of all students who came into the Centre. Over cups of tea and walks she and I had many critical conversations about learning and helping others learn. In my undergraduate degree her practice of care demonstrated to me that I was visible and that she believed in me. She introduced me to liberatory practice in education, but never called it that.

As a graduate mentor at Portland State I gained formal tools and more language to bring greater equity and care into a classroom. This was enhanced through studying peace education in my graduate work. I have been mulling over the facultymentor dance. I have gotten to perform the dance as a mentor and as faculty. As a mentor my dance partners were the faculty partner, and the students. At times the dance with the faculty was being their back up and making them look good. At times it was teaching students the steps to master the class and to satisfy the faculty partner, and sometimes it was translating the class' needs to the faculty partner. At 
times the dance between mentor and faculty is seen by students, and at times not. At times my dance was enhanced by the faculty partner, at times not. I think there is care involved in all of that, for sure, in that the mentor's explicit responsibility is to build and be a relational bridge within the course. This last part-translating needs from one side to the otheris where the dance can get challenging, and at times can break down.

In my second year of mentoring I partnered with a faculty partner new to teaching in University Studies. The faculty partner and I had a great beginning. We liked each other. I understood where things were going in the class. As the term went on, a major disconnect began between the faculty partner and the students. Students struggled with writing. The faculty was unable to meet students here. The class progressed with a deep divide between students and faculty around their respective expectations of each other and the class. Both felt unseen and disregarded by each other. From an ethic of care perspective I tried to meet students where they were, and to improve their performance over the term. Faculty partners in the past had mostly ascribed to this thinking. They were University Studies veterans and were for the most part open to the students in our classes. At that time University Studies had a learning goal that all classes expose students to the "Diversity of Human Experience." ${ }^{\prime \prime}$ As a mentor, I took that to mean both a requirement to expose students to the diversity of human experience in material and perspectives, and to embrace the diversity of backgrounds, education levels, and life that comes into our classrooms. As a faculty, particularly for newer faculty to University Studies, embracing the diversity of students both as people and learners can be the hardest part.

In our class the faculty-student relationship imploded and students began to lean more heavily on me as the mentor to help them through the class. The faculty did not appreciate this, and our relationship became strained. There is a power 
differential between the faculty partner and mentor. It is not the mentor's class, though the mentor is not a bystander. In our dance the faculty partner and I stepped on each other and could not understand each other's moves.

Now as a faculty partner teaching FRINQ and SINQ I work with mentors. As a faculty I try to anchor some assignments in mentor sections. Doing this encourages students to take mentor sections seriously and gives the mentor a measure of autonomy. Graduate mentors in particular often bring pedagogical skills from their professional and academic lives that can enrich the class. Strong mentor, faculty relationships meet weekly and when we are working well together there is a strong flow of information between us. However, even in the best of times students can feel distant from the faculty partner due to the inherent power distance between student and teacher. Students may feel that they are closer to the mentor because the mentor is a type of peer. The mentor is not grading them and there is a lesser power distance between mentor and students. They share a common identity as students at the university.

I think back to the example I offered about a class that went wrong. Now I have a greater empathy for the faculty partner. Structuring a class to hold a diverse group of learners is hard. It requires that we structure assignments differently. Scaffolding of assignments and more targeted learning objectives are critical. This is not intuitive. One of the challenges and the opportunities of University Studies courses is that students come to them from a variety of disciplines. Students are not always clear about the course they have signed up for. As a faculty we are dancing with students who recognize what we are doing in the classroom and others who do not or feel that they are being forced into an academic experience that they do not necessarily want or value. As a faculty, teaching in University Studies has stretched my pedagogy more than teaching in my disciplines. For faculty we only get better at this dance with 
praxis, the practice and reflection on pedagogical practice highlighted by bell hooks (1994).

In a recent FRINQ class I struggled in my dance with students. I had a strong relationship with the mentor, but could not connect with students despite many attempts. I found that students began to relate more with the mentor than with me as the faculty partner. The students did not see a lot of my work in structuring the class or in setting up an environment for them as critical thinkers, one of the University Studies goals. Students adored their mentor but struggled to understand what I asked of them as critical interdisciplinary thinkers. Students wanted me to teach to a test rather than invite stronger reflection and analysis of material. Though I offered students room to reflect and engage with course content, students were resistant.

As a faculty partner it is disconcerting to have mentors connect with students more than I. The mentor was critical in translating assignments and encouraging students to continue. In some ways it required that I share some of my power with the mentor in a way that I had not done before. I look back on that class with mixed emotions. Students produced quality work that drew on multiple disciplines, felt disconnected from me, and struggled to understand the value of their work. I have a sense that both the faculty and the mentor need to improve our ability to help students articulate what they have done as they forge through inquiry classes. Students must be able to articulate why we do the dance or what the dance has meant. The e-portfolio gets at that to some extent, but I think that articulation must happen throughout the learning process. This is different than simply completing assignments to get through a course. Developing shared understanding around the process of learning is a part of a care ethic. It's a challenge! Joe, how about for you? What sense do you make of this question of care as a practice and as a thread between your experiences as a student, a mentor, and a teacher? 
It started with that "Pop Culture" class and Paolo, but the process of change really gained steam when I became a mentor. I was accepted into a community of teachers and learners that was characterized by trust and mutual support. On a nearly daily basis, I was the beneficiary of care from fellow mentors, faculty partners, and those who administered the program. My perspective on my role was shaped early on when I asked for advice from seasoned mentors about how to approach my first mentor section. Ian McCann (a graduate student with a couple of years of mentoring under his belt) told me to go into the classroom telling myself that I would remember everyone's name. A seemingly pedestrian piece of advice ended up serving as a guiding mantra, a constant reminder of the importance of relationships to my role as a mentor, in and out of the classroom.

When I think of my identity as a caring educator, my imagination turns to the multitude of times that I have intentionally participated in introductions, mentally repeating names and connecting them to their associated stories. I use storytelling as a means of engaging relationally with students. This is not always easy or without missteps. Storytelling has, from the very start, been a critical aspect of the pedagogy in my class. I share stories from my experience, not only to illustrate concepts that are being taught, but to model reflective practice and encourage students to do the same. Every week, at the start of class, I ask them to share something about their weekly service in local schools. When things go well, sharing these stories exposes a variety of perspectives, provides an opportunity for group problemsolving, and as a result, creates trust and understanding within the learning community of our classroom. At times our stories hit each other in painful places. As a facilitator I am thinking about my role in maintaining the learning community. I seek to preserve the integrity of how we communicate and at times it can get away from me. Sometimes it is me who is learning from the students in this regard. 

exercises to help us listen deeply to each other, to speak, and to actively listen to ourselves. Stories open a door for critical thinking. They invite reflection on personal and collective experiences. That is courageous. At times it's uncomfortable. Discomfort is a part of learning.

My experience of moving from different countries and between different racial and cultural groups is the experience of shifting into different spaces and trying to find spots of connection. Jones and Shorter-Gooden (2004) describe shifting as the experience of Black women moving into predominantly White work environments and the cultural and identity shifts that we make to successfully navigate the workplace. The practice of shifting helps me withstand some of the opposition I experience in the classroom. Shifting is something that all nondominant groups negotiate in the classroom to some extent. Shifting is a skill we are developing in students as we help them move beyond their experiences into a deeper conversation with others.

Earlier I shared about going to Wits. Wits was the seed of my desire to create greater belonging for underrepresented students in academia. To do this requires shifts in what we teach and how we teach. I want students to leave my classes, regardless of their backgrounds, with a greater understanding of themselves, their relation to the world, and broader perspectives beyond their familiar. I appreciate that University Studies shares this mandate.

Joe, I am grateful for our time together. It is rare to talk about our positionalities and its impact on teaching. I do not think that I would be a teacher now without having been a mentor. Mentoring gave me a window into academia that made it appear possible. I got a sense of how the teacher got into the front of the room, and I experienced myself as capable in that role.

Both of us were invited to teach as faculty when we completed our graduate degrees. University 
JW:

Studies has benefitted from an informal cadre of people who have filled multiple roles in the program and the academy overtime. We are examples of the benefits of persistence. I think the most successful faculty stay with University Studies for a longer time. Doing this well takes time and iterations of practice. Mentoring was my impetus for pursuing teaching, and when it came time for me to go looking, I found an open door waiting for me. Shortly after graduating from my master's program, I was invited to temporarily fill an open office position in the department. Then, another faculty left a course that was seemingly tailored to my combined experiences. This was lucky, and no one explicitly laid this path before me. Mentoring groomed me for the work that I would do afterward. Like you say, it's not a formal path, but upon reflection, it sometimes feels like one. So much of what we do in our mentoring roles constitutes critical experience in preparation for teaching most effectively within this unique model. And, I think, those of us who stick around tend to be those who are most aware of the immense value our efforts can have for our peers, and who are deeply - perhaps, personally - affected by our work as mentors.

In the end, ours are only two stories, and we might be in the minority. We've described a clear connection between our experiences in the program and our decisions to remain here as faculty. So much of what we learned as mentors informs our practice now. Reflection is a skill we developed then that helps us now.

Thinking about care and "how we teach, is what we teach," I hope to teach students how to care-in a productive way-for what they do and how it affects the people and the world around them. While it is sometimes explicit in the curriculum, the real work gets done in how I demonstrate to my students that I genuinely care about the relationships that I build with them. And, I've observed this same commitment in many of our colleagues-in how they interact with students and with me. 
I too am truly grateful for our conversations together, Roberta. I have learned quite a bit through sharing stories with you. Thank you!

ROBERTA HUNTE works as an assistant professor in Child Youth and Family Studies at the School of Social Work at Portland State University. She teaches Freshman Inquiry, Senior Inquiry, and Sophomore Inquiry in the University Studies program. She has a PhD in Peace and Conflict Studies from the University of Manitoba, an MS in Conflict Resolution from Portland State University, and a BA in Politics and English from the University of the Witwatersrand.

JOSEPH WIGHTMAN teaches as an adjunct instructor in PSU's University Studies Senior Capstone program. He earned his BA in International Studies: Latin America and an MS.Ed.: Postsecondary Adult Continuing Education from Portland State University.

\section{NOTE}

1. The Diversity of Human Experience learning goal's name and definition has since changed to Diversity, Equity, and Social Justice. The move to the DESJ goal will be discussed later in this special volume.

\section{WORKS CITED}

Freire, P. (1970). Pedagogy of the oppressed (A Continuum book). New York: Herder and Herder. hooks, b. (1994). Teaching to transgress: Education as the practice of freedom. New York: Routledge. Jones, C., \& Shorter-Gooden, K. (2004). Shifting: The double lives of Black women in America (First Perennial ed.). New York: Perennial. 